\title{
INSTITUTION OF ELECTRONICS EXHIBITION IN MANCHESTER
}

$\mathrm{T}$ HE ninth Annual Exhibition of Electronic Devices, organized by the North-West Branch of the Institution of Electronies, was held in the Manchester College of Technology during July 14-20. The Exhibition was as large and efficiently organized as any of its predecessors, and was as deservedly popular. It included, in addition to exhibits in the commercial and research sections, a programme of general and specialized lectures, and a number of illustrative film shows. For an affair of this sizesome forty exhibitors were represented-a detailed review cannot be given; the writer must restrict his attention to a few of the features which he found most interesting.

The commercial section was impressive chiefly for its evidence of steady progress in the development of known techniques. Applications of television were prominent, and there were on view no fewer than three industrial closed-circuit television channels (by Pye, Philips Electrical, and J. Langham Thompson). Low-inertia integrating motors were shown by Electro Methods, Ltd. ; these motors have practically straight voltage-speed characteristics, and are used for time integration of minute voltages. The Saunders-Roe exhibit included some interesting and, incidentally, very handsome strain gauges. These are made of metal foil etched into suitable strainsensitive patterns, and mounted on an epoxy resin lacquer backing. They are more robust than conventional wire gauges, and permit a higher input current without compromising stability. Part of the large Mullard exhibit consisted of a formidable array of ultrasonic devices. Among them was an ultrasonic drill press, designed for the drilling or machining, by the action of an abrasive slurry between the vibrating tool and the work, of such intractable materials as glass. Equipment for the ultrasonic cleaning of fragile or inaccessible objects, and an ultrasonic soldering-iron capable of dealing with aluminium, were also demonstrated.

Prominent in the research section were the stands of the British Rayon Research Association. Among the recently developed instruments on display was an ingeniously simple autocorrelogram computer, used for the separation of periodic from random irregularities in yarns. The same exhibit included a demonstration of equipment used in flash photolysis. In this technique an intensely bright flash of short duration is used for irradiating a specimen, and after a selected interval of 20 usec. or more, a second, less bright, but shorter, flash is used to record the absorption spectrum of the specimen. In this way the presence and decay of short-lived products of irradiation can be studied.

The Institute of Cancer Research exhibited ultrasonic echo-locating equipment, used for the examination of brain structure. When the equipment is in use, a quartz transducer in acoustic contact with the head emits a narrow, pulsed beam of ultrasound. Any echoes incident on the transducer are transmitted as pulses through amplifier and display circuits, and appear on an oscillograph screen. The position of the pulse on the screen gives a measure of the distance of the source of the echo from the transducer. At present, observations are being com- pared with what is known of the 'normal' brain, with the view of the possible identification of abnormal structures. In view of the drastic effects of ultrasonic vibrations, as demonstrated in the Mullard exhibit, it should be mentioned that the power output of the transducer is only $30 \mu \mathrm{W}$. Since the vibrations suffer considerable attenuation on entering and leaving the skull, it is clear that high sensitivity is required of the amplifiers.

A portable twelve-channel toposcope, designed as an aid to the increasingly important subject of electroencephalography, was exhibited by the Burden Neurological Institute. The complete study of the simultaneous electrical activity associated with a number of points on the head, for a significant period, is bound to be almost prohibitively time-consuming. The purpose of the toposcope is to restrict severely the type of information to be studied, and to present it in a rational manner. The equipment can be set for a desired frequency, or alternatively it can be made to set itself servo-mechanically for the pre. dominant signal frequency of any selected channel, and in this condition it is sensitive only to that frequency or its harmonics. The display panel consists of a number of cathode-ray tubes, and each of these indicates for one of the channels (that is, for one of the selected points on the head) which, if any, of the harmonics of the driving signal is present, and what its relative phase is. A larger version of the equipment has been in use at the Burden Institute for the past two years, and has proved to be of particular value in research on the functional anatomy of the brain.

The Exhibition as a whole has proved to be of the highest interest to very many visitors, and due credit must be paid to the exhibitors and organizers alike.

A. W. Hanson

\section{BRITISH CAST IRON RESEARCH ASSOCIATION OPEN DAY}

$\mathrm{T}$ THE British Cast Tron Research Association, Birmingham, held an open day on July 7 for representatives of member-firms, some three hundred of whom attended, being welcomed by the president, Sir Frederick Scopes. The next day some hundred. and fifty attended from other research associations, government laboratories, trade associations, technical institutions, universities, technical colleges and schools.

The extensions last reported (Nature, 170, 153; 1952) have been fully brought into use, except for the new melting shop, which has yet to be equipped, but which in the meantime is being used for work on foundry atmospheres. The Association has been negotiating with the Department of Scientific and Industrial Research with respect to arrangements for its new grant period, during which it is hoped a further stage of expansion will be reached.

A feature which attracted considerable interest was a display of art castings in moulded iron, in- 